2. National Lung Screening Trial Research Team. Reduced lung-cancer mortality with low-dose computed tomographic screening. N Engl J Med. 2011;365:395-409.

3. Clark SD, Reuland DS, Enyioha C, Jonas DE. Assessment of lung cancer screening program websites. JAMA Intern Med. 2020;180:824-30.

4. Ho H, Williamson C, Regis SM, Stock CT, Quardri SM, McKee BJ, et al. Surgery and invasive diagnostic procedures for benign disease are rare in a large low-dose computed tomography lung cancer screening program. J Thorac Cardiovasc Surg. 2021;161:790-802.e2.

5. Bauml JM, Troxel A, Epperson CN, Cohen RB, Schmitz K, Stricker C, et al. Scanassociated distress in lung cancer: 1uantifying the impact of "scanxiety" Lung Cancer. 2016;100:110-3.
6. Tailor TD, Tong BC, Gao MJ, Henderson LM, Choudhury KR, Rubin GD. Use of lung cancer screening in the Medicare fee-for-service population. Chest. June 17, 2020 [Epub ahead of print].

7. Zahnd WE, Eberth JM. Lung cancer screening utilization: a behavioral risk factor surveillance system analysis. Am J Prev Med. 2019;57:250-5.

8. Sabatino SA, White MC, Thompson TD, Klabunde CN. Cancer screening test use-United States, 2013. MMWR Morb Mortal Wkly Rep. 2015;464-8.

9. Mazzone P, Powell CA, Arenberg D, Bach P, Detterbeck F, Gould MK, et al. Components necessary for high-quality lung cancer screening: American College of Chest Physicians and American Thoracic Society Policy Statement. Chest. 2015;147:295-303.
See Article page 790.

\section{Commentary: We need more surgeons!}

\section{Daniel P. Raymond, MD}

Many remember the release of the National Lung Screening Trial $^{1}$ and the excitement it generated. What followed was a flurry of planning in anticipation of a huge influx of lung nodules patient requiring multidisciplinary management. I personally remember discussions about increasing surgical resources to handle the surge in patients, even recruiting new surgeons! Unfortunately, that surge was more of a trickle. Even after the Centers for Medicare and Medicaid Services approved lung cancer screening (LCS) as a benefit in 2015, the prevalence of screening in appropriate populations remains $<20 \%{ }^{2}$

Ho and colleagues ${ }^{2}$ take an in-depth look at a reason for this poor performance-concern regarding unnecessary invasive procedures - in their recent study. They first point out the evolution of LCS since the original release of the NLST trial 9 years ago. Their program has adopted the use of Lung CT Screening Reporting \& Data System for nodule reporting, which has increased the positive predictive value 2.5 -fold. In combination with the standardization

From Lerner College of Medicine, Cleveland Clinic Thoracic \& Cardiovascular Surgery, Cleveland, Ohio.

Disclosures: The author reported no conflicts of interest.

The Journal policy requires editors and reviewers to disclose conflicts of interest and to decline handling or reviewing manuscripts for which they may have a conflict of interest. The editors and reviewers of this article have no conflicts of interest.

Received for publication Aug 20, 2020; revisions received Aug 20, 2020; accepted for publication Aug 20, 2020; available ahead of print Aug 29, 2020.

Address for reprints: Daniel P. Raymond, MD, Lerner College of Medicine, Cleveland Clinic Thoracic \& Cardiovascular Surgery, 9500 Euclid Ave, J4-1, Cleveland, OH 44195 (E-mail: raymond3@ccf.org).

J Thorac Cardiovasc Surg 2021;161:804-5

$0022-5223 / \$ 36.00$

Copyright (c) 2020 by The American Association for Thoracic Surgery

https://doi.org/10.1016/j.jtcvs.2020.08.073
Check for updates

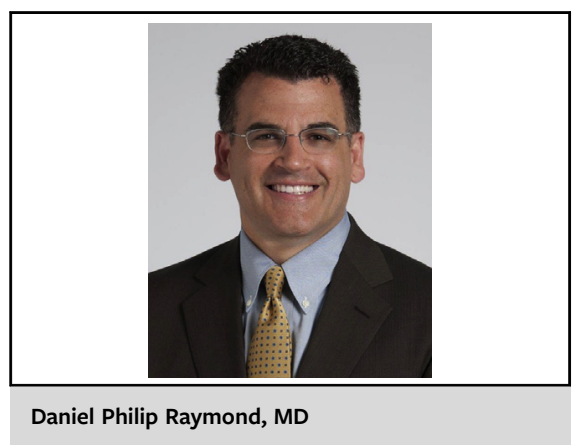

CENTRAL MESSAGE

The risk of unnecessary invasive

procedures for benign disease

due to lung cancer screening is

$<1 \%$.

of a multidisciplinary approach, this has resulted in a significant decrease in the use of invasive tests from roughly $10 \%$ in the NLST to $2.6 \%$ in the current trial. As a result, the ultimate probability of undergoing any invasive procedure for nonmalignant disease in a screened patient was $0.95 \%$; surgery was $0.43 \%$.

When counseling patients, what do we say? The benefit of LCS is well documented. If the patient or practitioner expresses concern about unnecessary testing, we now have excellent data to allay those fears. Based on this study, $30 \%$ of patients with a Lung CT Screening Reporting \& Data System category 4 will have a malignancy. The probability of an unnecessary invasive test using the Lahey system to evaluate that malignancy is $<1 \%$. With additional testing and clinical judgment, if an invasive diagnostic test is deemed necessary, the chances of cancer rise to roughly $50 \%$. Of those tests, a disappointingly low number $(6 \%)$ will reveal a specific benign diagnosis, 
roughly $40 \%$ of the time we are left with a nondiagnostic test and have to go back to square 1. If surgery is ultimately deemed necessary, $80 \%$ will find lung cancer, even if based on clinical characteristics and without biopsy. When surgery is required, minimally invasive techniques are now the accepted standard, whereas such techniques were used a minority of the time in the NLST. Most importantly, if cancer is discovered, $60 \%$ of the time it is an earlier, curable stage, a dramatic change from $39 \%$ in unscreened populations. ${ }^{3}$

Our challenge remains to disseminate this information and educate patients and practitioners regarding the significant value of LCS. Success could mean prevention of $52 \%$ of lung cancer deaths. ${ }^{2}$ Clearly we must succeed. Maybe then, we will need more surgeons.

\section{References}

1. National Lung Screening Trial Research Team, Aberle DR, Adams AM, Berg CD Black WC, Clapp JD, et al. Reduced lung cancer mortality with low-dose computed tomographic screening. N Engl J Med. 2011;365:395-409.

2. Ho H, Williamson C, Regis SM, Stock CT, Quadri SM, McKee BJ, et al. Surgery and invasive diagnostic procedures for benign disease are rare in a large low-dose computed tomography lung cancer screening program. J Thorac Cardiovasc Surg. 2021;161:790-802.e2.

3. National Cancer Institute Surveillance, Epidemiology, and End Results Program Cancer stat facts: lung and bronchus cancer. Available at: https://seer.cancer.gov/ statfacts/html/lungb.html. Accessed August 15, 2020.
See Article page 790.

\section{Commentary: Overcoming the dangerous narrative of computed tomography screening for lung cancer}

\author{
Brendon M. Stiles, MD
}

Einstein once said, "The world is not dangerous because of those who do harm but because of those who look at it without doing anything." Low dose computed tomography for lung cancer screening (LCS) should be considered in the context of this statement. Despite the National Lung Screening Trial (NLST) and Dutch-Belgian Lung Cancer Screening trial, which clearly demonstrate a reduction in lung cancer mortality, LCS rates of eligible patients fall well below those of

From the Department of Cardiothoracic Surgery, Weill Cornell Medicine, New YorkPresbyterian Hospital, New York, NY.

Disclosures: Dr Stiles is a consultant for AstraZeneca, Pfizer, and Flame Biosciences; has been a part of advisory boards/received speaking fees for Bristol Myers Squibb, Genentech, Ribon Therapeutics, and PeerView; and is a board member of the Lung Cancer Research Foundation.

The Journal policy requires editors and reviewers to disclose conflicts of interest and to decline handling or reviewing manuscripts for which they may have a conflict of interest. The editors and reviewers of this article have no conflicts of interest.

Received for publication Aug 20, 2020; revisions received Aug 20, 2020; accepted for publication Aug 20, 2020; available ahead of print Aug 28, 2020.

Address for reprints: Brendon M. Stiles, MD, Department of Cardiothoracic Surgery, Weill Cornell Medicine, New York-Presbyterian Hospital, 525 E 68th St, M404,

New York, NY 10065 (E-mail: Brs9035@med.cornell.edu).

J Thorac Cardiovasc Surg 2021;161:805-6

$0022-5223 / \$ 36.00$

Copyright (c) 2020 Published by Elsevier Inc. on behalf of The American Association for Thoracic Surgery

https://doi.org/10.1016/j.jtcvs.2020.08.074

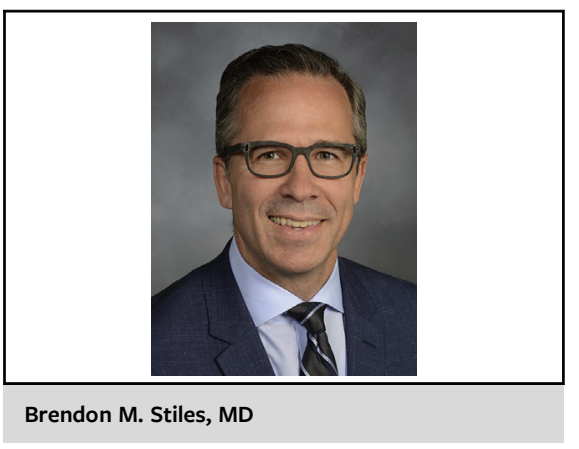

CENTRAL MESSAGE

Too many people overestimate

the perceived harms of

computed tomography

screening for lung cancer.

Detected nodules can be safely

managed with exceedingly low

rates of major complications.

other common cancers such as breast, colon, cervical, and prostate cancer. Arguably, the benefits of LCS established by the large, modern NLST and Dutch-Belgian Lung Cancer Screening trials are superior to historical screening data for these other cancers for which screening is more broadly applied. However, LCS had the misfortune of coming of age during a time in which a skepticism of cancer screening was on the rise in general. Additionally, there has been a tremendous focus on the harms of LCS, both in the medical literature and in the popular press. But to just cite the generic term harms and major complications as a reason not to 